\title{
Insulin Resistance and Low Folate Levels Are Associated With Hyperthyroidism in Graves' Disease
}

Neves $\mathrm{C}^{1,4}$, Esteves $\mathrm{C}^{1,4}$, Neves $\mathrm{JS}^{1,4}$, Sokhatska $\mathrm{O}^{2}$, Pereira $\mathrm{M}^{1}$, Palmares $\mathrm{C}^{2}$, Dias $\mathrm{C}^{3}$, Carvalho $\mathrm{D}^{1,4}$, Delgado $\mathrm{L}^{2,4}$, Medina JL

${ }^{1}$ Department of Endocrinology, Diabetes and Metabolism; ${ }^{2}$ Department of Immunology; ${ }^{3}$ Department of Health Information and Decision Sciences; São João Hospital Centre. ${ }^{4}$ Faculty of Medicine, University of Porto

\section{Background}

Besides their effects on the cardiovascular system, thyroid hormones are also a key metabolic regulator.

So, it is possible that the higher cardiovascular risk in Graves' disease may be due not only to hemodynamic changes induced by the hyperthyroid state, but also to alterations in the cardiovascular risk factor profile.

Aim

To evaluate the interrelationships between thyroid function, insulin resistance, lipid profile, homocysteine, CRP (C-reactive protein), folic acid and vitamin B12 levels, in Graves' disease (GD).

\section{Patients and Methods}

- We recorded thyroid function tests, BMI, insulin resistance markers comprising the Homeostasis Model Assessment for insulin resistance (HOMA-IR), the Quantitative Insulin Sensitivity Check Index (QUICKI), HISI (Hepatic Insulin Sensitivity Index), WBISI (Whole-Body Insulin Sensitivity Index), IGI (Insulinogenic Index) and the levels of total cholesterol (TC), HDL, LDL-cholesterol, triglycerides (TG), apolipoprotein B (ApoB), ApoA1, lipoprotein(a) (Lp[a]), homocysteine, CRP (C-reactive protein), folic acid and vitamin B12 levels in 104 subjects with Graves' disease in the first cycle of treatment with methimazole, ( $94 \%$ female). The subjects were classified into two groups: 49 patients were included in the hyperthyroid group (fT3 $>3.71 \mathrm{pg} / \mathrm{mL}$ and/or $\mathrm{fT} 4>1.48 \mathrm{ng} / \mathrm{dL}$ and $\mathrm{TSH}<0.35 \mu \mathrm{UI} / \mathrm{mL}$ ) and 55 in the euthyroid group.

- Mann-Whitney test, logistic regression and Pearsons's correlations were used for statistical analysis. Results were adjusted for age and BMI. A twotailed $p<0.05$ was considered statistically significant.

Results

Characteristics of the patients enrolled in the study

\begin{tabular}{|l|c|c|c|} 
& $\begin{array}{c}\text { Hyperthyroidism } \\
(\mathrm{n}=49)\end{array}$ & $\begin{array}{c}\text { Euthyroidism } \\
(\mathrm{n}=55)\end{array}$ & $p$ value \\
\hline $\begin{array}{l}\text { Sex, } \mathrm{n}(\%) \\
\text { Females }\end{array}$ & $46(94)$ & $52(95)$ & - \\
\hline $\begin{array}{l}\text { Males } \\
\text { Age, years }\end{array}$ & $3(6)$ & $3(5)$ & \\
\hline $\mathrm{BMI}, \mathrm{kg} / \mathrm{m}^{2}$ & $24.75(22.45-28.92)$ & $24.82(21.48-28.58)$ & 0.699 \\
\hline $\mathrm{TSH}, \mu \mathrm{UI} / \mathrm{mL}$ & $0.01(0.00-0.13)$ & $1.34(0.75-1.78)$ & $<0.001$ \\
\hline $\mathrm{fT}, \mathrm{pg} / \mathrm{mL}$ & $3.17(2.64-4.09)$ & $2.75(2.43-3.15)$ & 0.002 \\
\hline $\mathrm{fT4}, \mathrm{ng} / \mathrm{dL}$ & $1.25(1.05-1.45)$ & $1.03(0.90-1.14)$ & $<0.001$ \\
\hline TRAb, UI/mL & $3.2(1.5-12.1)$ & $1.1(0.5-2.0)$ & $<0.001$ \\
\hline Folate, ng/mL & $5.1(3.6-6.5)$ & $6.9(5.1-9.4)$ & 0.001 \\
\hline WBISI & $4.39(2.49-6.15)$ & $5.50(4.08-7.79)$ & 0.015 \\
\hline
\end{tabular}

\section{Results}

- Significantly higher levels of TRAb $(\mathrm{Ul} / \mathrm{mL})$ were found in the hyperthyroid patients [3.2(1.5-12.1) vs $1.1(0.5-2.0), p<0.001]$

- The levels of folate $(\mathrm{ng} / \mathrm{mL})$ and WBISI were significantly lower in the hyperthyroid group $[(5.1(3.6-6.5)$ vs $6.9(5.1-9.4), p=0.001 ; 4.39(2.49-6.15)$ vs $5.50(4.08-7.79), p=0.015]$.

Across all patients we found the following correlations:

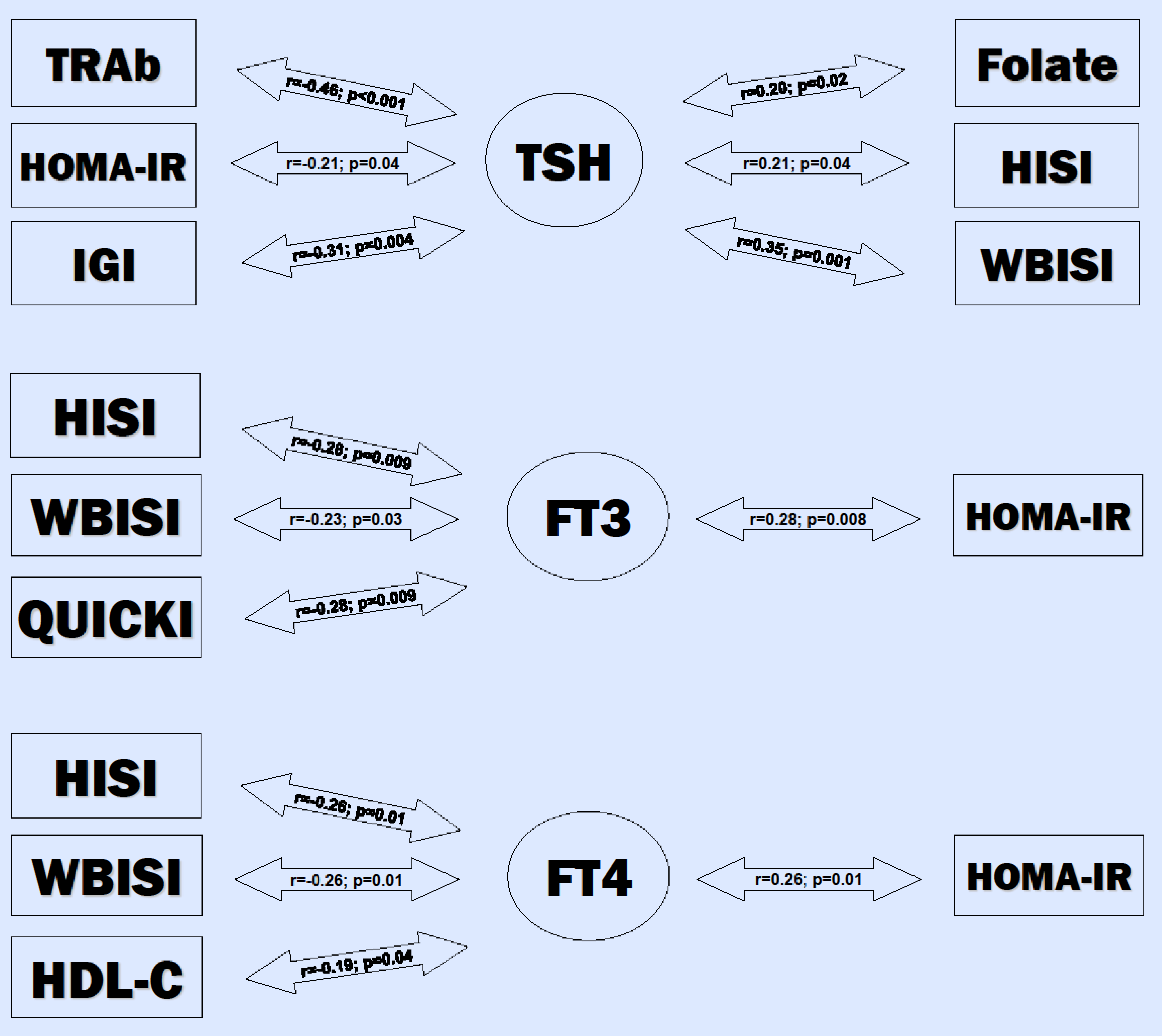

In the Hyperthyroid patients we found the following correlation:

FT3

LP(a)

In the Euthyroid patients we found the following correlation:

\section{FT3}

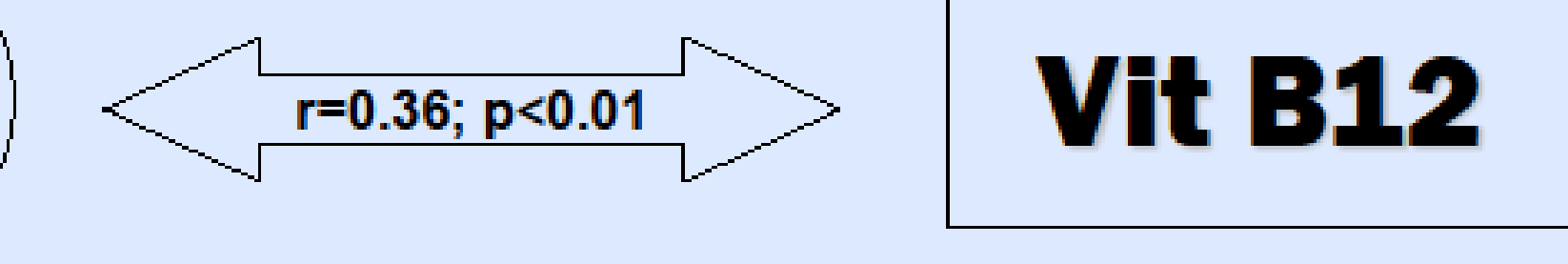

\section{Conclusions}

We found that patients with higher levels of TRAb and insulin resistance had a higher risk of being hyperthyroid in Graves disease. On the other hand, patients with higher folate levels had a lower risk of being hyperthyroid. 